TITLE:

\title{
Property of critical excitation for moment-resisting frames subjected to horizontal and vertical simultaneous ground motions
}

\section{$\operatorname{AUTHOR}(\mathrm{S}):$}

Fujita, Koji; Takewaki, Izuru

\section{CITATION:}

Fujita, Koji ... [et al]. Property of critical excitation for moment-resisting frames subjected to horizontal and vertical simultaneous ground motions. Journal of Zhejiang University Science A 2009, 10(11): 1561-1572

ISSUE DATE:

2009-11

URL:

http://hdl.handle.net/2433/89635

\section{RIGHT:}

この論文は出版社版でありません。引用の際には出版社版をご確認ご 利用ください。; This is not the published version. Please cite only the published version. 


\title{
Property of critical excitation for moment-resisting frames subjected to horizontal and vertical simultaneous ground motions
}

\author{
Kohei FUJITA, Izuru TAKEWAKI ${ }^{1}$ \\ Dept. of Urban \& Environmental Eng., Graduate School of Eng., \\ Kyoto University, Kyotodaigaku-Katsura Nishikyo, Kyoto 615-8540, Japan
}

\begin{abstract}
It has often been reported that, when building structures are subjected to near-fault earthquake ground motions, horizontal and vertical impulsive inputs during the first few seconds may cause critical damage. In practical design of building structures, however, the safety check taking into account the effect of multi-component ground motions is hardly conducted except the design of important structures such as high-rise buildings and nuclear power plants. Furthermore, it is not clear how the correlation of multi-component ground motions influences the actual safety of structures. In this paper, the detailed property of critical excitation is discussed in association with the relationship between the characteristics of ground motions and those of structures. The properties of various auto power spectral density (PSD) functions of the horizontal and vertical ground motions are investigated, and those of the critical cross power spectrum density function (critical cross PSD) of these two-directional ground motions are found by a devised algorithm in a feasible complex plane. A closed-form expression is derived of the critical relation of the auto PSD functions of the simultaneous inputs. This critical excitation method provides us with a new approach for earthquake-resistant design against the possible future earthquake which causes the critical damages to buildings.
\end{abstract}

Keywords: critical excitation, multi-component ground input, critical cross spectrum, coherency, simultaneous input

\footnotetext{
${ }^{1}$ Corresponding author, takewaki@archi.kyoto-u.ac.jp
} 


\section{INTRODUCTION}

After the Hyogoken-Nambu earthquake (1995), various discussions have been made on the possibility of occurrence and existence of impulsive and simultaneous inputs from horizontal and vertical directions to building structures (e.g. Japanese Geotechnical Society, 1996). This kind of great earthquake ground motions occurs in the long return period (Strasser and Bommer 2009) and it may be difficult to investigate the actual recorded ground motions of large intensity and with various properties.

In order to overcome this difficulty, several critical excitation approaches have been proposed and various useful methods have been provided (Drenick, 1970; Abbas and Manohar, 2002a, b, 2007; Abbas and Takewaki 2009; Iyengar and Manohar, 1987; Manohar and Sarkar, 1995; Sarkar and Manohar, 1996; Takewaki, 2001, 2002, 2004a, b, 2006a, b; Fujita et al, 2008). The work by Sarkar and Manohar $(1996,1998)$ and Abbas and Manohar (2002b) are concerned with the present paper although their papers deal with different models of multiple inputs at different points. Sarkar and Manohar (1996, 1998) formulated an interesting problem and solved the problem within the framework of limited variables. In particular, they treat only correlation in terms of 'the absolute value' of the cross PSD function (root mean square of sum of the squares of co-spectrum and quad-spectrum). On the other hand, Abbas and Manohar (2002b) presented another interesting method including detailed analysis of cross-correlation between multiple inputs at different points.

In most of the current structural design practice of building structures, safety and functionality checks are made with respect to one-directional earthquake input. It may also be understood that an approximate safety margin is incorporated in the magnitude of one-directional input. However a more reliable method is desired (for example see Smeby and Der Kiureghian 1985 for multi-component input). In this paper, horizontal and vertical simultaneous ground motions are treated and critical aspects of these ground motions are discussed in detail. The combinations of auto PSD functions of 
respective inputs are key parameters for discussion. A closed-form expression of the critical relation of the auto PSD functions of simultaneous inputs is derived and detailed analysis of the critical relation is provided.

\section{ANALYSIS OF COHERENCE OF RECORDED BI-DIRECTIONAL GROUND MOTIONS}

In this paper, the coherence function is assumed to be fixed at 1.0. This assumption means that horizontal and vertical ground motions are fully correlated, but it is not commonly known what degree of correlation the multi-component ground motions have. For this reason, it is meaningful to investigate the correlation between recorded bi-directional ground motions.

Fig.1(a-1) shows the representative acceleration records of El Centro NS and UD (Imperial Valley 1940), Fig.1(b-1) those of NIG018 NS and UD (Niigataken Chuetsu-oki 2007), and Fig.1(c-1) those of JMA Kobe NS and UD (Hyogoken-Nambu 1995). Table 1 indicates the area (power) of the auto PSD function of these ground motions. For these data, Figs.2(a-c) indicate the distribution of coherence functions for three time intervals. The auto PSD functions and cross PSD functions have been calculated from the Fourier transforms by using the Welch-Bartlett's method. As shown in Figs.1(a-2, b-2, c-2), the starting time of the window with the duration $T$ (5s in El Centro, NIG018 and JMA Kobe) was changed successively (time-lag of 0.02s for El Centro and JMA Kobe and 0.01s for NIG018) and the corresponding set of data for the 50 windows was chosen to represent candidates of the ensemble mean. Then the ensemble mean was taken of the functions computed from the Fourier transforms. It can be observed that the coherence strongly depends on the type of earthquake ground motions. Furthermore, it has been investigated that the coherence also depends on the portion of ground motions. The prediction of the coherence function before its occurrence is quite difficult and the critical excitation method will provide a meaningful 
insight even in these circumstances.

\section{MODELING OF HORIZONTAL AND VERTICAL STOCHASTIC GROUND MOTIONS}

It is assumed here that horizontal and vertical simultaneous ground motions (HVGM) can be described by the following uniformly modulated non-stationary model.

$$
\begin{aligned}
& \ddot{u}_{g}(t)=c_{u}(t) w_{u}(t) \\
& \ddot{v}_{g}(t)=c_{v}(t) w_{v}(t)
\end{aligned}
$$

where $c_{u}(t), c_{v}(t)$ are the envelope functions and $w_{u}(t), w_{v}(t)$ are the stationary random processes (zero-mean Gaussian). The time lag between the horizontal and vertical ground motions can be expressed in terms of $c_{u}(t), c_{v}(t)$.

The envelope function $c_{u}(t)$ is given by

$$
\begin{array}{ll}
c_{u}(t)=(t / 3.0)^{2} & (0 \leq t \leq 3) \\
c_{u}(t)=1.0 & (3 \leq t \leq 12.5) \\
c_{u}(t)=e^{-0.24(t-12.5)} & (12.5 \leq t \leq 40)
\end{array}
$$

The envelope function $c_{v}(t)$ can also be given by Eq.(3). Fig.3(a) shows an example of the envelope function.

The stationary random processes (zero-mean Gaussian) $w_{u}(t), w_{v}(t)$ can be generated from the auto PSD functions. Given these two functions, the multi-component ground motion can then be generated by the multiplication of these functions (see Fig.3(b)).

\section{STRUCTURAL MODEL SUBJECTED TO HORIZONTAL AND VERTICAL SIMULTANEOUS GROUND INPUTS}

Consider a moment-resisting frame subjected to HVGM. The columns have a square-tube cross section and the beams have a wide-flange cross section as shown in 
Fig.4. The storey height is $H$ and the span length of the frame is $L$. Let $E, I_{b}, I_{c}$ denote the Young's modulus of the beam and columns, the second moment of area of beam and that of column, respectively.

Assume that the vibration in each direction of the moment-resisting frame can be expressed by the single-degree-of-freedom (SDOF) model. The equivalent horizontal and vertical stiffnesses $k_{u}, k_{v}$ of the SDOF model is expressed respectively by (Fujita et al. 2008b)

$$
\begin{aligned}
& k_{u}=\frac{12 E I_{c}\left\{1+6\left(I_{b} / I_{c}\right) \cdot(H / L)\right\}}{H^{3}\left\{2+3\left(I_{b} / I_{c}\right) \cdot(H / L)\right\}} \\
& k_{v}=\frac{96 E I_{b}\left\{2+\left(I_{b} / I_{c}\right) \cdot(H / L)\right\}}{L^{3}\left\{1+2\left(I_{b} / I_{c}\right) \cdot(H / L)\right\}}
\end{aligned}
$$

The bending moments at the beam-end under the respective input of HVGM may be expressed by

$$
\begin{aligned}
& M_{u}(t)=\frac{18 E I_{b}}{H L\left\{2+3\left(I_{b} / I_{c}\right) \cdot(H / L)\right\}} u(t) \equiv A_{M u} u(t) \\
& M_{v}(t)=\frac{24 E I_{b}}{L^{2}\left\{1+2\left(I_{b} / I_{c}\right) \cdot(H / L)\right\}} v(t) \equiv A_{M v} v(t)
\end{aligned}
$$

$u(t)=$ horizontal displacement of node B and $v(t)=$ vertical displacement of the central point of floor.

Let $\omega_{u}=\sqrt{k_{u} / m_{u}}, \omega_{v}=\sqrt{k_{v} / m_{v}}$ denote the fundamental natural circular frequencies in the horizontal and vertical vibrations, respectively, of the SDOF model. The horizontal and vertical displacements of the floor can be derived as

$$
\begin{aligned}
& u(t)=\int_{0}^{t}\left\{-\ddot{u}_{g}(\tau)\right\} g_{u}(t-\tau) d \tau \\
& v(t)=\int_{0}^{t}\left\{-\ddot{v}_{g}(\tau)\right\} g_{v}(t-\tau) d \tau
\end{aligned}
$$

where $g_{u}(t), g_{v}(t)=$ unit impulse response functions. 
By using Eqs.(6)-(9), $M_{u}(t)$ and $M_{v}(t)$ can be expressed as

$$
\begin{aligned}
& M_{u}(t)=A_{M u} \int_{0}^{t}\left\{-\ddot{u}_{g}(\tau)\right\} g_{u}(t-\tau) d \tau \\
& M_{v}(t)=A_{M v} \int_{0}^{t}\left\{-\ddot{v}_{g}(\tau)\right\} g_{v}(t-\tau) d \tau
\end{aligned}
$$

\section{STOCHASTIC RESPONSE IN FREQUENCY DOMAIN}

The bending moments at the beam-end under the respective input of HVGM is expressed by the sum of responses to each direction as bellow

$$
f(t)=M_{u}(t)+M_{v}(t)
$$

The auto-correlation function of $f(t)$ can be expressed by

$$
\begin{aligned}
E\left[f\left(t_{1}\right) f\left(t_{2}\right)\right]= & E\left[M_{u}\left(t_{1}\right) M_{u}\left(t_{2}\right)\right]+E\left[M_{u}\left(t_{1}\right) M_{v}\left(t_{2}\right)\right] \\
& +E\left[M_{v}\left(t_{1}\right) M_{u}\left(t_{2}\right)\right]+E\left[M_{v}\left(t_{1}\right) M_{v}\left(t_{2}\right)\right]
\end{aligned}
$$

where $E[$ ] denotes the ensemble mean. Eq.(13) consists of four terms in time domain. These terms will be evaluated in detail in the following.

The auto-correlation function of the bending moment due to the horizontal input, i.e. the first term in Eq.(13), can be formulated in frequency domain by (Fujita et al. 2008b)

$$
\begin{aligned}
& E\left[M_{u}(t)^{2}\right] \\
& =A_{M u}{ }^{2} \int_{-\infty}^{\infty}\left[\left\{\int_{0}^{t} c_{u}(\tau) g_{u}(t-\tau) \cos \omega \tau d \tau\right\}^{2}+\left\{\int_{0}^{t} c_{u}(\tau) g_{u}(t-\tau) \sin \omega \tau d \tau\right\}^{2}\right] S_{u u}(\omega) d \omega \\
& =A_{M u}{ }^{2} \int_{-\infty}^{\infty}\left[B_{c}(t ; \omega)^{2}+B_{s}(t ; \omega)^{2}\right] S_{\text {uи }}(\omega) d \omega
\end{aligned}
$$

where

$$
\begin{aligned}
& B_{c}(t ; \omega)=\int_{0}^{t} c_{u}(\tau) g_{u}(t-\tau) \cos \omega \tau d \tau \\
& B_{s}(t ; \omega)=\int_{0}^{t} c_{u}(\tau) g_{u}(t-\tau) \sin \omega \tau d \tau
\end{aligned}
$$

The auto-correlation function of the bending moment due to the vertical input, i.e. 
the fourth term in Eq.(13), can be expressed as follows by the same procedure developed for the first term.

$$
E\left[M_{v}(t)^{2}\right]=A_{M u}{ }^{2} \int_{-\infty}^{\infty}\left[C_{c}(t ; \omega)^{2}+C_{s}(t ; \omega)^{2}\right] S_{v v}(\omega) d \omega
$$

where

$$
\begin{aligned}
& C_{c}(t ; \omega)=\int_{0}^{t} c_{v}(\tau) g_{v}(t-\tau) \cos \omega \tau d \tau \\
& C_{s}(t ; \omega)=\int_{0}^{t} c_{v}(\tau) g_{v}(t-\tau) \sin \omega \tau d \tau
\end{aligned}
$$

The cross-correlation function of the bending moment due to HVGM can be formulated by some manipulations. The cross-correlation function of the functions $w_{u}(t)$ and $w_{v}(t)$ can be expressed in terms of the cross PSD function $S_{u v}(\omega)$ described by

$$
E\left[w_{u}\left(\tau_{1}\right) w_{v}\left(\tau_{2}\right)\right]=\int_{-\infty}^{\infty}\left\{C_{u v}(\omega)+\mathrm{i} Q_{u v}(\omega)\right\} e^{\mathrm{i} \omega\left(\tau_{1}-\tau_{2}\right)} d \omega
$$

where $C_{u v}(\omega)$ and $Q_{u v}(\omega)$ are the real part (co-spectrum) and imaginary part (quad-spectrum) of $S_{u v}(\omega)$, respectively (Nigam, 1981). By substituting Eq.(20) into the cross-correlation function in frequency domain, the cross term, i.e. the sum of the second and third terms in Eq.(13), can be written by

$$
\begin{aligned}
& E\left[M_{u}(t) M_{v}(t)\right]+E\left[M_{v}(t) M_{u}(t)\right] \\
& =2 A_{M_{u}} A_{M_{v}} \int_{-\infty}^{\infty}\left\{f_{1}(t ; \omega) C_{u v}(\omega)+f_{2}(t ; \omega) Q_{u v}(\omega)\right\} d \omega
\end{aligned}
$$

where

$$
\begin{aligned}
& f_{1}(t ; \omega)=B_{c}(t ; \omega) C_{c}(t ; \omega)+B_{s}(t ; \omega) C_{s}(t ; \omega) \\
& f_{2}(t ; \omega)=B_{c}(t ; \omega) C_{c}(t ; \omega)-B_{s}(t ; \omega) C_{s}(t ; \omega)
\end{aligned}
$$

Finally, the mean-squares of the sum of bending moments at beam-end may be expressed by 


$$
\begin{aligned}
E & {\left[\left\{M_{u}(t)+M_{v}(t)\right\}^{2}\right] } \\
=A_{M u}{ }^{2} \int_{-\infty}^{\infty}\left\{B_{C}(t ; \omega)^{2}+B_{s}(t ; \omega)^{2}\right\} S_{u u}(\omega) d \omega & \\
& +2 A_{M u} A_{M v} \int_{-\infty}^{\infty}\left\{f_{1}(t ; \omega) C_{u v}(\omega)+f_{2}(t ; \omega) Q_{u v}(\omega)\right\} d \omega \\
& +A_{M v}{ }^{2} \int_{-\infty}^{\infty}\left\{C_{C}(t ; \omega)^{2}+C_{s}(t ; \omega)^{2}\right\} S_{v v}(\omega) d \omega
\end{aligned}
$$

\section{CRITICAL EXCITATION METHOD FOR WORST CROSS PSD FUNCTION OF HVGM}

The critical excitation problem may be stated as: Find the cross PSD function $S_{12}(\omega)=C_{12}(\omega)+\mathrm{i} Q_{12}(\omega)$ of HVGM so as to achieve $\max _{S_{u v}(\omega)} \max _{t} E\left[\left\{M_{u}(t)+M_{v}(t)\right\}^{2}\right]$.

When $t$ is fixed and $\omega$ is specified, the transfer functions $f_{1}(t ; \omega)$ and $f_{2}(t ; \omega)$ defined in Eqs.(22a, b) can be regarded as pre-determined coefficients, not functions of $t$ and $\omega$. Therefore the integrand in the second term of Eq.(23) can be regarded as the function $z\left(C_{u v}, Q_{u v}\right)$ of $C_{u v}$ and $Q_{u v}$.

$$
z\left(C_{u v}, Q_{u v}\right)=f_{1}(t ; \omega) C_{u v}(\omega)+f_{2}(t ; \omega) Q_{u v}(\omega)
$$

Fig.5 illustrates the structure of the critical excitation problem. The critical excitation problem is to maximize the function $z\left(C_{u v}, Q_{u v}\right)$ under the constraint $C_{u v}{ }^{2}+Q_{u v}{ }^{2}=$ $S_{u u}(\omega) S_{v v}(\omega)$. This constraint corresponds to the assumption of the existence of a fully correlated multi-component ground input. The critical co-spectrum and quad-spectrum can then be obtained analytically as (Fujita et al., 2008a, b)

$$
\begin{aligned}
& C_{u v}(\omega)=f_{1}(t ; \omega) \frac{\sqrt{S_{u u}(\omega) S_{v v}(\omega)}}{\sqrt{f_{1}(t ; \omega)^{2}+f_{2}(t ; \omega)^{2}}} \\
& Q_{u v}(\omega)=f_{2}(t ; \omega) \frac{\sqrt{S_{u u}(\omega) S_{v v}(\omega)}}{\sqrt{f_{1}(t ; \omega)^{2}+f_{2}(t ; \omega)^{2}}}
\end{aligned}
$$

Fig.6 indicates the solution algorithm. By substituting Eqs.(25) and (26) into Eq.(21), Eq.(21) can be rewritten as the worst cross term maximizing the response 
quantity.

$$
\begin{aligned}
& E\left[M_{u}(t) M_{v}(t)\right]+E\left[M_{v}(t) M_{u}(t)\right] \\
& =2 A_{M u} A_{M v} \int_{-\infty}^{\infty} \sqrt{f_{1}(t ; \omega)^{2}+f_{2}(t ; \omega)^{2}} \sqrt{S_{u u}(\omega) S_{v v}(\omega)} d \omega
\end{aligned}
$$

Finally, Eq.(27) gives the closed-form worst cross term. In the integrand of Eq.(27), it

can be observed that the property (transfer function $\sqrt{f_{1}(t ; \omega)^{2}+f_{2}(t ; \omega)^{2}}$ ) of a structure and that $\sqrt{S_{u u}(\omega) S_{v v}(\omega)}$ of ground motions are given separately. It can be understood that the relation between $S_{u u}(\omega)$ and $S_{v v}(\omega)$ is the key factor for the criticality (see Fig.7).

\section{CLOSED-FORM EXPRESSION OF THE WORST COMBINATION OF PSD FUNCTIONS}

It can also be observed from Eq.(27) that the increase of response due to the correlation between multi-component ground motions from the SRSS response is indirectly related with the integration $\int_{-\infty}^{\infty} \sqrt{S_{u u}(\omega) S_{v v}(\omega)} d \omega$ of geometric mean of both auto PSD functions. Under the constraint that the properties (shape) of respective auto PSD functions of ground motions are given (e.g. through the square of the velocity design spectrum (Fujita et al., 2008a, b)), the critical correlation in Eq.(27) can be calculated based on the properties of a structure. However, since there may exist uncertainties with respect to the auto PSD functions of ground motions, it does not seem enough to consider the critical excitation problem under the constraint mentioned above. For this reason, let us find the worst combination of auto PSD functions which maximize the structural response under the constraint that the powers (areas) of the auto PSD functions are constant.

Iyenger and Manohar (1987) expressed the square root of the PSD function of the excitation in terms of linear combination of orthonormal function and determine their coefficients through eigenvalue analysis. Takewaki (2001) introduces more simple 
probabilistic approach to define the PSD function as a band limited white noise (rectangle one). In the problem for one-directional input, the critical PSD function can be given by the resonant band limited white noise, not the velocity design spectrum, under the constraint that the area of the PSD function and the upper bound of the PSD function are given (see Fig.8). In this paper, the central circular frequencies of the PSD functions of HVGM are assumed to be given by the resonant ones.

As a constraint on the excitations, the following ones are introduced.

$$
\begin{aligned}
& \int_{-\infty}^{\infty} S_{u u}(\omega) d \omega \leq \bar{S}_{u} \\
& \int_{-\infty}^{\infty} S_{v v}(\omega) d \omega \leq \bar{S}_{v}
\end{aligned}
$$

The value of $\bar{S}_{u}$ and $\bar{S}_{v}$ should be given appropriately according to the analysis of the auto PSD functions of recorded earthquake ground motions.

When $\omega_{u}, \omega_{v}$ denote the fundamental natural circular frequencies in the horizontal and vertical directions of the structure and $\Omega_{U}, \Omega_{V}$ express halves of the band widths of the auto PSD functions in the horizontal and vertical directions (Fig.9), the term $\int_{-\infty}^{\infty} \sqrt{S_{u u}(\omega) S_{v v}(\omega)} d \omega$ can be expressed as

$$
\int_{-\infty}^{\infty} \sqrt{S_{u u}(\omega) S_{v v}(\omega)} d \omega=\sqrt{\frac{\alpha}{\Omega_{U} \Omega_{V}}} \bar{S}_{u}\left\{\left(\Omega_{U}+\Omega_{V}\right) / 2-\left|\omega_{u}-\omega_{v}\right|\right\}
$$

where $\alpha=\bar{S}_{v} / \bar{S}_{u}$. In Eq.(29), it has been assumed that the central frequency of the auto PSD function coincides with the natural frequency of the structural model in both directions. The stationary point of Eq.(29) with respect to $\Omega_{U}, \Omega_{V}$ can be derived by differentiating Eq.(29) with respect to $\Omega_{U}, \Omega_{V}$. The solution can be obtained as

$$
\Omega_{U}=\Omega_{V}=2\left|\omega_{u}-\omega_{v}\right|
$$

Eq.(30) implies that, if $\omega_{u}=\omega_{v}, \Omega_{U}=\Omega_{V}=0$. This indicates that the worst input is the Dirac delta function in each direction in this model. However it should be noted 
that the simplification from Eq.(27) into Eq.(29) is approximate and a fairly large error may arise depending on the model.

\section{NUMERICAL ANALYSIS}

The structural model analyzed in this section is shown in Fig.10. Two models with the span lengths $L=17(\mathrm{~m})$ and $24(\mathrm{~m})$ are treated. The given geometrical and structural parameters are shown in Tables 2 and 3. Fig.11 illustrates the transfer functions $\sqrt{f_{1}(t ; \omega)^{2}+f_{2}(t ; \omega)^{2}}$ for these two models. It can be observed that, while a simple and clear peak exists in the model of $L=17(\mathrm{~m})$ due to the coincidence of both natural frequencies, a complex form arises in the model of $L=24(\mathrm{~m})$ due to the non-coincidence of both natural frequencies. Table 1 shows the values of $\bar{S}_{u}$ and $\bar{S}_{v}$ for the above-mentioned recorded ground motions. The maximum value of $\bar{S}_{u}$ is less than $9\left(\mathrm{~m}^{2} * \mathrm{rad} / \mathrm{s}^{4}\right)$. Based on this analysis, $\bar{S}_{u}$ and $\bar{S}_{v}$ are given by $10\left(\mathrm{~m}^{2} * \mathrm{rad} / \mathrm{s}^{4}\right)$ and $2.5\left(\mathrm{~m}^{2} * \mathrm{rad} / \mathrm{s}^{4}\right)$.

Fig.12 compares the root-mean-square of the bending moment due to the critical combination of multi-input with that due to the SRSS response without correlation terms. The left figure is drawn for the model of $L=17(\mathrm{~m})$ and the right one is drawn for the model of $L=24(\mathrm{~m})$. These figures are plotted with respect to $\Omega_{V}$ for the fixed horizontal input circular frequency $\Omega_{U}=5(\mathrm{rad} / \mathrm{s})$. It can be observed that, while in the model of $L=24(\mathrm{~m})$ the difference between the bending moment due to the critical combination of multi-input and that due to the SRSS response is very small, that is fairly large in the model of $L=17(\mathrm{~m})$.

According to Eq.(30), the stationary value of $\Omega_{V}$ is about $0.1(\mathrm{rad} / \mathrm{s})$ in the model of $L=17(\mathrm{~m})$. However, Fig.12 indicates that the maximum correlation term occurs around $0.2-0.5(\mathrm{rad} / \mathrm{s})$. This may result from the approximation employed in the derivation of Eqs.(29) and (30). On the other hand, the stationary value of $\Omega_{V}$ is about 5.8(rad/s) in the model of $L=24(\mathrm{~m})$. This corresponds fairly well with Fig.12(b). 
In the case of narrow band of $\Omega_{U}$ and $\Omega_{V}$, the bending moment tends to be increased by the resonance effect. In addition, the bending moment can also be increased by the input correlation effect. Taking into account these two effects, the occurrence possibility of the worst combination of auto PSD functions can be investigated for each structural model (see Fig.13). Fig.13(a) for the model of $L=17(\mathrm{~m})$ indicates that the close location of natural frequencies in the horizontal and vertical directions causes the critical combination of auto PSD functions of HVGM as the largely overlapped shape. On the other hand, Fig.13(b) for the model of $L=24(\mathrm{~m})$ illustrates that the separated location of natural frequencies in the horizontal and vertical directions provides the critical combination of auto PSD functions of HVGM as the un-overlapped shape.

Figs.14(a-1) and (a-2) show the 3D comparison of the root-mean-square of the bending moment to the critically correlated multi-input with that to the multi-input without correlation for the model of $L=17(\mathrm{~m})$ with respect to $\Omega_{U}$ and $\Omega_{V}$. On the other hand, Figs.14(b-1) and (b-2) illustrate the corresponding comparison for the model of $L=24(\mathrm{~m})$. It is found that, while the model of $L=17(\mathrm{~m})$ exhibits a remarkable difference between both cases, the model of $L=24(\mathrm{~m})$ indicates a similar property between both cases. The influence of the band-widths of the auto PSD functions on the critical response can be observed clearly from these 3D figures.

Fig.15 illustrates the quantity of Eq.(27) for the critically correlated multi-input with respect to $\Omega_{U}$ and $\Omega_{V}$ for the models of $L=17(\mathrm{~m})$ and $24(\mathrm{~m})$. While the fundamental natural frequency of the model in the horizontal direction is almost equal to that in the vertical direction in the model of $L=17(\mathrm{~m})$, both are different in the model of $L=24(\mathrm{~m})$. These characteristics may cause the difference in Fig.15.

\section{CONCLUSIONS}

A new stochastic model of multi-component ground motion has been proposed in 
which the critical cross PSD function between the horizontal and vertical ground motions (HVGM) can be directly treated in the feasible complex plane. The following conclusions have been derived.

1. A critical excitation problem has been formulated for a moment-resisting frame subjected to HVGM. These multi-component ground motions are characterized by a non-stationary stochastic model consisting of a given deterministic envelope function and a stochastic zero-mean Gaussian process.

2. The mean-squares bending moment at the beam-end has been shown to be the sum of the independent term due to each of HVGM and that due to their correlation. Each term have been formulated in the frequency domain. In the cross term of HVGM, the real part (co-spectrum) and imaginary part (quad-spectrum) of the cross PSD function can be regarded as independent variables. Since the auto PSD functions of HVGM are given and prescribed, the maximization in the critical excitation problem means the maximization of their correlation term.

3. The co-spectrum and quad-spectrum of the worst cross PSD function can be obtained by a devised algorithm including the interchange of the double maximization procedure in the time and cross PSD function domains. These expressions and the corresponding critical response have been described in closed form.

4. A closed-form expression of the critical relation of the auto PSD functions of simultaneous inputs has been derived in association with the relation with the horizontal and vertical structural properties.

5. Numerical examples indicate that the proposed algorithm can work very well. The root-mean-square of the bending moment at the beam-end to the critical combination of the HVGM can become fairly larger than that by the SRSS estimate depending on the relation of the auto PSD functions of simultaneous inputs with the horizontal and vertical structural properties. The overlapping area of the auto PSD 
functions of HVGM in the frequency domain directly influences the critical cross PSD function between HVGM. These investigations have been made possible via the closed-form solutions stated above.

6. The coherence function between the HVGM of recorded earthquakes has been calculated and compared with the assumption introduced here. The coherence and cross PSD functions strongly depend on the type of earthquake ground motions and its portion. The prediction of coherence before their occurrence seems quite difficult. The critical excitation method will provide a meaningful insight even in these circumstances.

For simple and clear presentation of the essence of the formulation, a simple SDOF system has been treated in this paper. The extension of the present formulation to MDOF or continuum models with finite-element discretization will be conducted in the future.

\section{Acknowledgements}

Part of the present work is supported by the Grant-in-Aid for Scientific Research of Japan Society for the Promotion of Science (No.18360264, 21360267). This support is greatly appreciated.

\section{References}

Abbas, A.M. and Manohar, C.S., 2002a. Investigating into critical earthquake load models within deterministic and probabilistic frameworks. Earthq. Engrg. Struct. Dyn., 31(4), 813-832.

Abbas, A.M. and Manohar, C.S., 2002b. Critical spatially varying earthquake load models for extended structures. J. Struct. Engrg., 29(1), 39-52 
Abbas, A.M. and Manohar, C.S., 2007. Reliability-based vector nonstationary random critical earthquake excitations for parametrically excited systems. Struct. Safety, 29, 32-48.

Abbas, A.M. and Takewaki, I., 2009. The use of probabilistic and deterministic measures to identify unfavorable earthquake records. J. Zhejiang UniversitySCIENCE A, 10(5), 619-634

Drenick, R.F., 1970. Model-free design of aseismic structures. J. Engrg. Mech. Div., ASCE, 96(EM4), 483-493

Fujita, K., Yoshitomi, S., Tsuji, M. and Takewaki, I., 2008a. Critical cross-correlation function of horizontal and vertical ground motions for uplift of rigid block, Engrg. Structures, 30(5), 1199-1213.

Fujita, K., Takewaki, I., and Nakamura, N., 2008b. Critical disturbance for stress resultant in long-span moment-resisting frames subjected to horizontal and vertical simultaneous ground inputs, J. Struct. Construction Engrg., AIJ, 626, 551-558 (in Japanese).

Iyengar, R.N., and Manohar, C.S., 1987. Nonstationary random critical seismic excitations. J. Engrg. Mech., ASCE, 113(4), 529-541.

Japanese Geotechnical Society, 1996. Special issue on geotechnical aspects of the January 171995 Hyogoken- Nambu Earthquake, Soils and Foundations.

Manohar, C.S., and Sarkar, A., 1995. Critical earthquake input power spectral density function models for engineering structures. Earthq. Engrg. Struct. Dyn., 24, 1549-1566.

Nigam, N.C., 1981. Introduction to Random Vibrations, MIT Press.

Sarkar, A., and Manohar, C.S., 1996. Critical cross power spectral density functions and the highest response of multi-supported structures subjected to multi-component earthquake excitations. Earthq. Engrg. Struct. Dyn., 25, 303-315.

Smeby, W., and Der Kiureghian, A., 1985. Modal combination rules for multicomponent 
earthquake excitation. Earthq. Engrg. Struct. Dyn., 13, 1-12.

Strasser, F.O., and Bommer, J.J., 2009. Large-amplitude ground-motion recordings and their interpretations. Soil Dyn. Earthq. Engrg., 29(10), 1305-1329.

Takewaki, I., 2001. A new method for nonstationary random critical excitation. Earthq. Engrg. Struct. Dyn., 30(4), 519-535.

Takewaki, I., 2002. Seismic critical excitation method for robust design: A review. $J$. Struct. Engrg., ASCE, 128(5), 665-672.

Takewaki, I., 2004a. Critical envelope functions for non-stationary random earthquake input. Computers \& Structures, 82(20-21), 1671-1683.

Takewaki, I., 2004b. Bound of earthquake input energy. J. Struct. Engrg., ASCE, 130(9), 1289-1297.

Takewaki, I., 2006a. Probabilistic critical excitation method for earthquake energy input rate. J. Engrg. Mech., ASCE, 132(9), 990-1000.

Takewaki, I., 2006b. Critical Excitation Methods in Earthquake Engineering, Elsevier Science, Oxford. 
Table 1 Area of auto PSD function for recorded ground motion

\begin{tabular}{|c|c|c|}
\hline Recorded ground motions & $\begin{array}{c}\text { Horizontal power } \\
\left(\mathrm{m}^{2} * \mathrm{rad} / \mathrm{s}^{4}\right)\end{array}$ & $\begin{array}{c}\text { Vertical power } \\
\left(\mathrm{m}^{2} * \mathrm{rad} / \mathrm{s}^{4}\right)\end{array}$ \\
\hline El Centro NS, UD (1940) & 1.478 & 0.365 \\
\hline NIG018 NS, UD (2007) & 8.878 & 2.253 \\
\hline JMA Kobe NS, UD (1995) & 8.001 & 1.733 \\
\hline
\end{tabular}

Table 2 Structural member properties

\begin{tabular}{|c|c|c|}
\hline cross-section & Column & beam \\
\hline $\begin{array}{c}\square-1000 \\
\times 1000 \times 30\end{array}$ & $\begin{array}{c}\mathrm{H}-1200 \\
\times 600 \times 40 \times 32\end{array}$ \\
\hline cross-sectional area $\left(\mathrm{mm}^{2}\right)$ & $1.16 \times 10^{5}$ & $8.38 \times 10^{4}$ \\
\hline second moment of area $\left(\mathrm{mm}^{4}\right)$ & $1.83 \times 10^{10}$ & $1.99 \times 10^{10}$ \\
\hline mass per unit length $(\mathrm{kg} / \mathrm{m})$ & 912 & 657 \\
\hline
\end{tabular}

Table 3 Geometrical and structural parameters

\begin{tabular}{|c|c|c|}
\hline Span length & $L=17.0 \mathrm{~m}$ & $L=24.0 \mathrm{~m}$ \\
\hline horizontal stiffness $k_{u}(\mathrm{~N} / \mathrm{mm})$ & $2.18 \times 10^{8}$ & $1.95 \times 10^{8}$ \\
\hline vertical stiffness $k_{v}(\mathrm{~N} / \mathrm{mm})$ & $1.07 \times 10^{8}$ & $4.16 \times 10^{7}$ \\
\hline mass in horizontal direction $m_{u}(\mathrm{~kg})$ & $1.79 \times 10^{6}$ & $2.70 \times 10^{6}$ \\
\hline mass in vertical direction $m_{v}(\mathrm{~kg})$ & $0.89 \times 10^{6}$ & $1.35 \times 10^{6}$ \\
\hline horizontal natural period $T_{u}(\mathrm{~s})$ & 0.569 & 0.741 \\
\hline vertical natural period $T_{v}(\mathrm{~s})$ & 0.572 & 1.131 \\
\hline
\end{tabular}


(a-1)

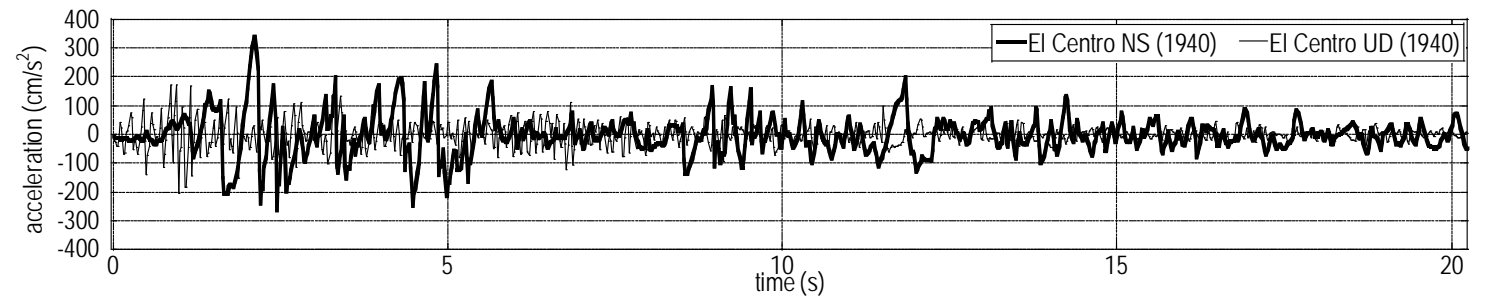

$(b-1)$

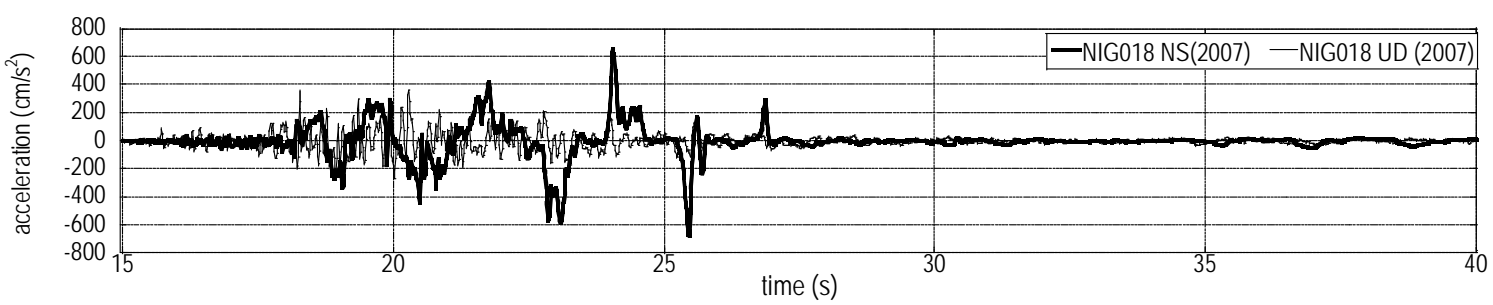

(c-1)

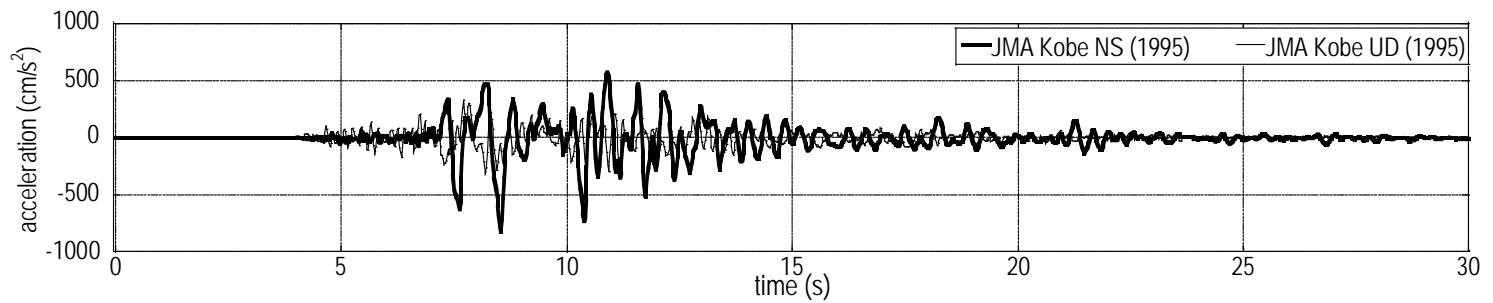

$(\mathrm{a}-2)$

(b-2)

$(\mathrm{c}-2)$
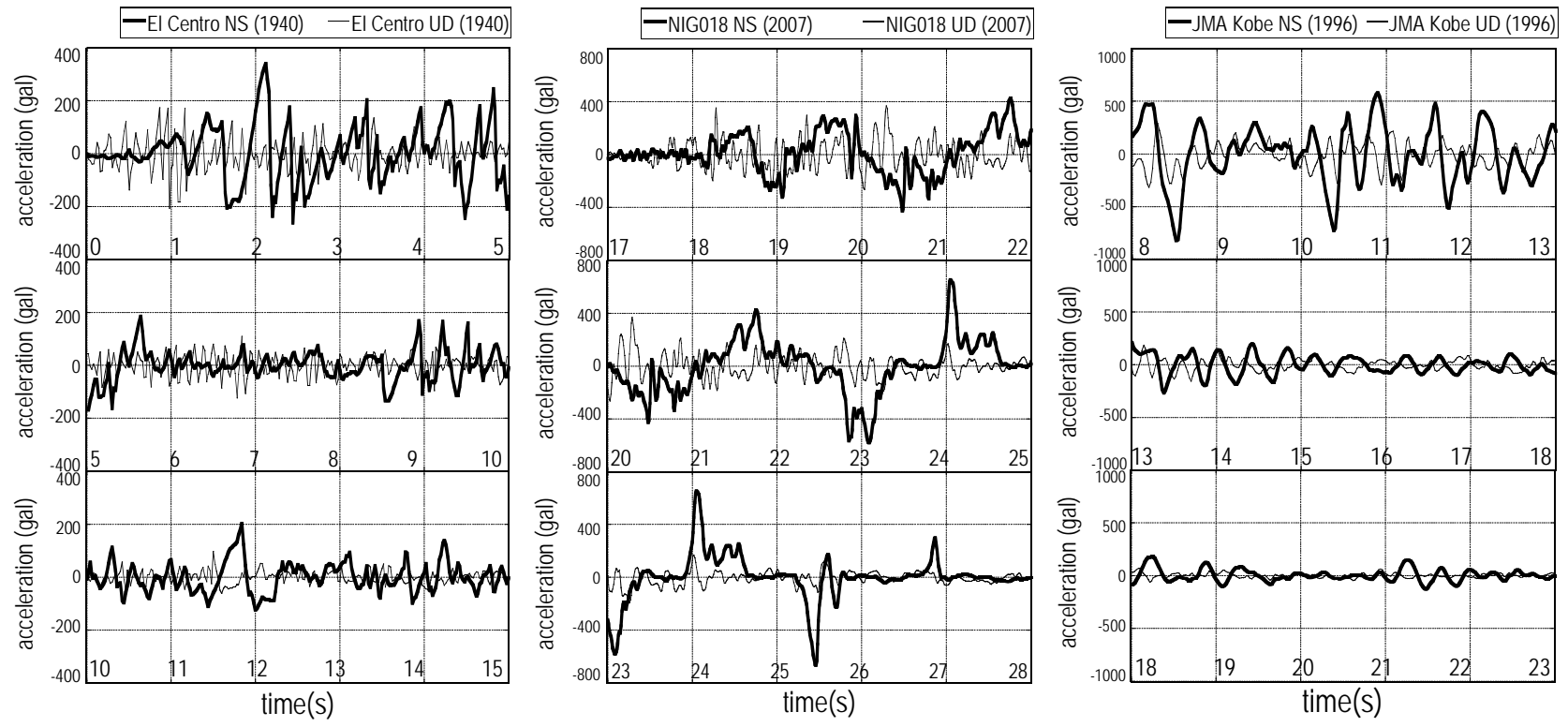

Figure 1 Acceleration records of

(a) El Centro 1940 NS and UD (Imperial Valley Earthquake)

(b) Nig 0182007 NS and UD ( Niigata-Ken Chuuetsu Oki earthquake)

(c) JMA Kobe 1995 NS and UD (Hyogo-Ken Nambu earthquake) 
(a)

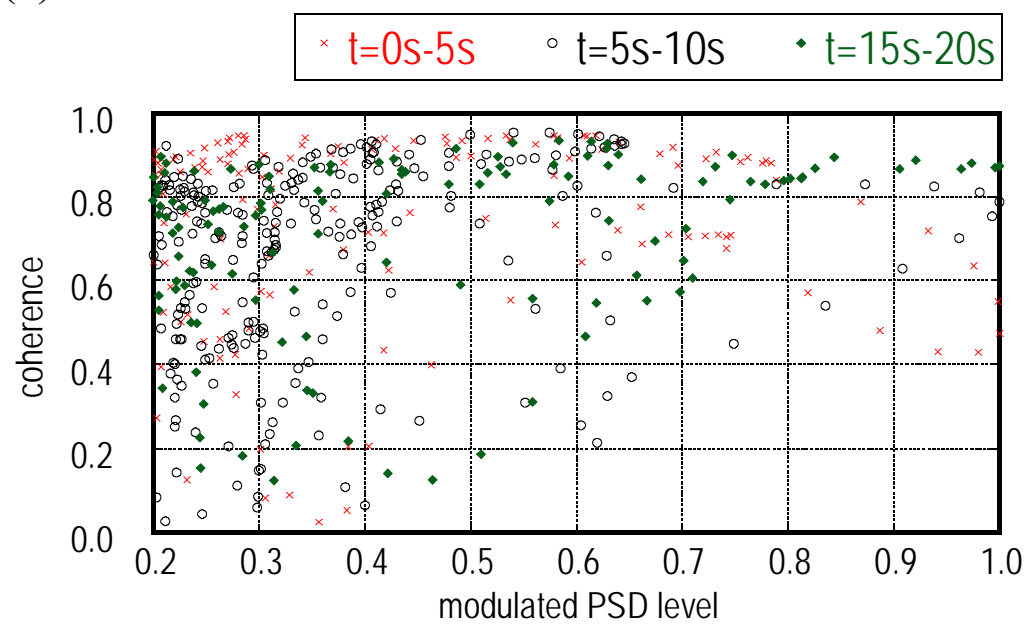

(b)

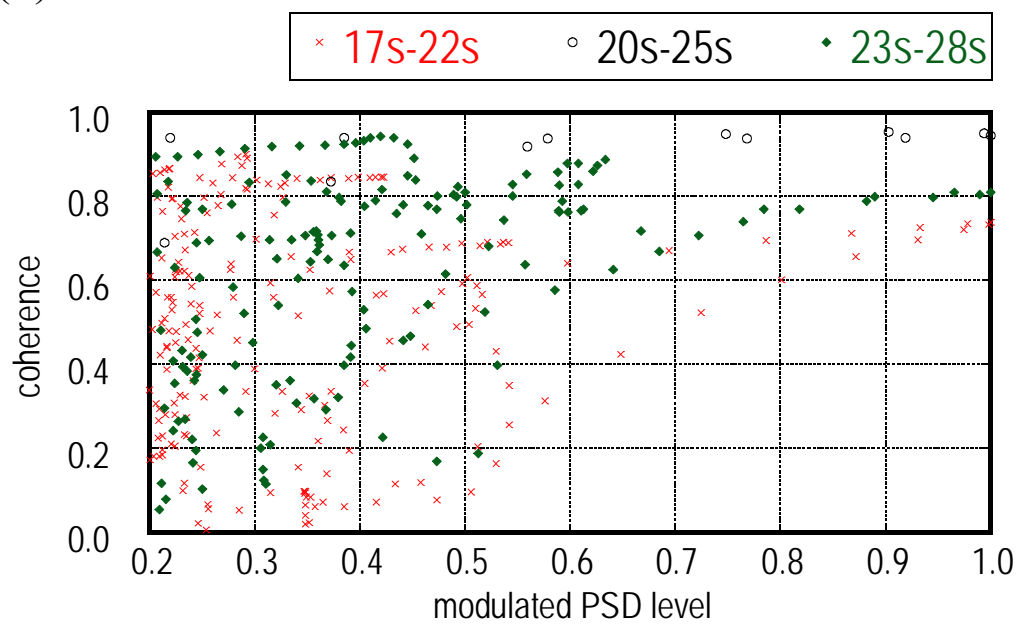

(c)

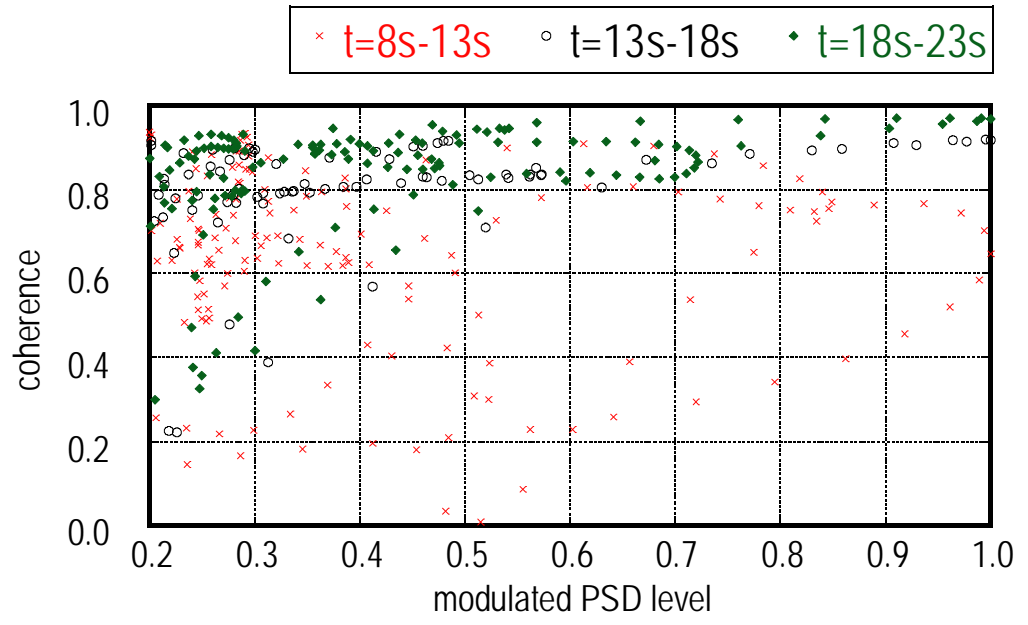

Figure 2 Coherence functions of recorded accelerations
(a) El Centro 1940 NS and UD (Imperial Valley Earthquake)
(b) Nig 0182007 NS and UD ( Niigata-Ken Chuuetsu Oki earthquake)
(c) JMA Kobe 1995 NS and UD (Hyogo-Ken Nambu earthquake) 
(a)

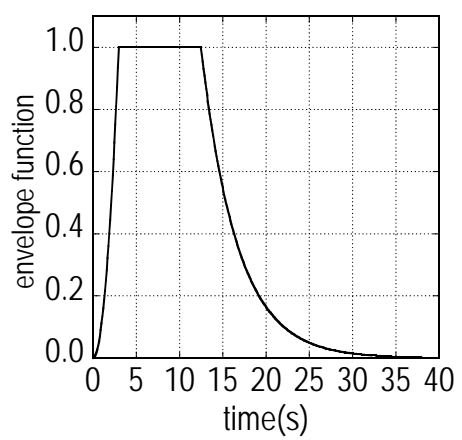

(b)

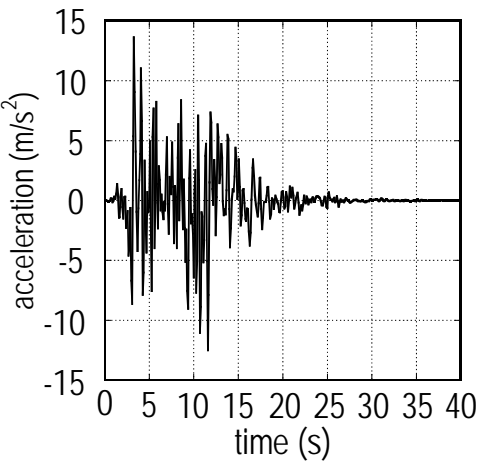

Figure 3 Example of non-stationary ground motion

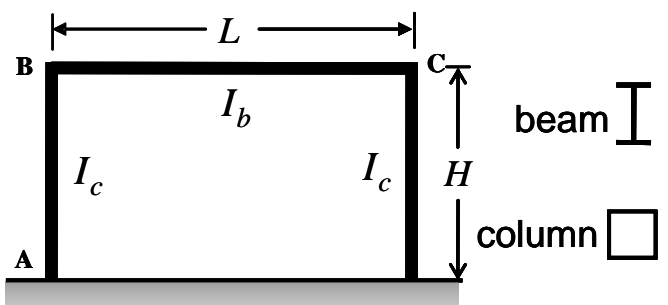

Figure 4 One-story one-span plane frame consisting of beam of wide-flange cross-section and column of square-tube cross-section

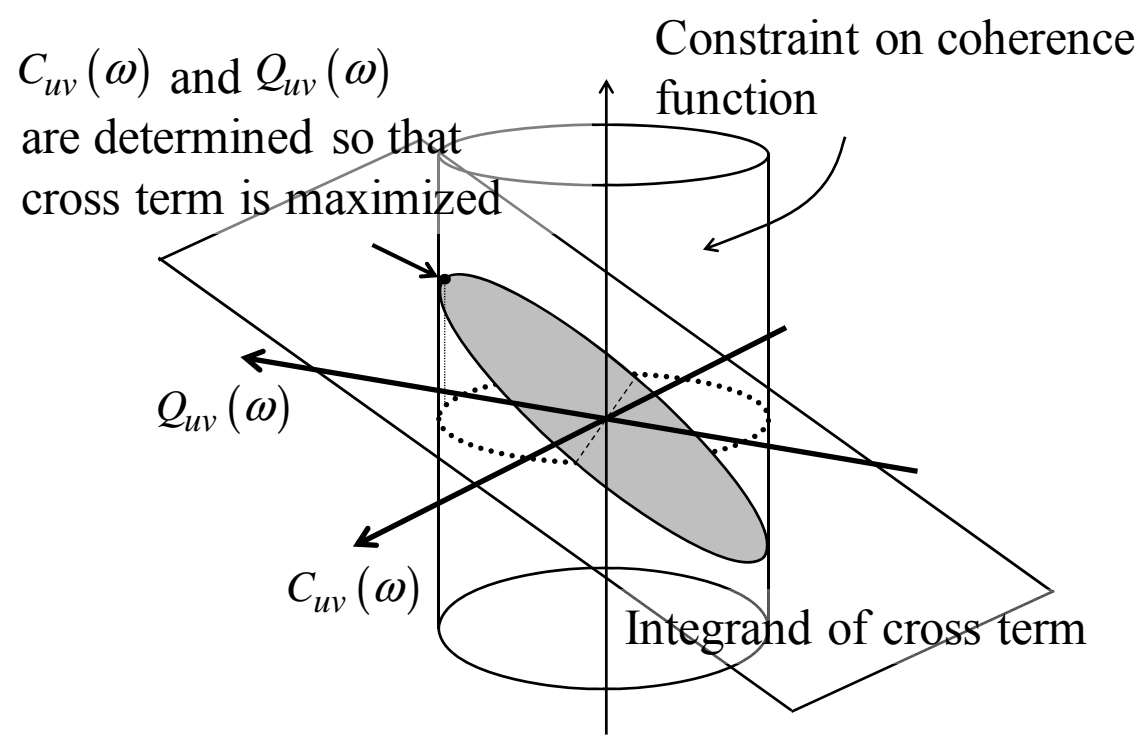

Figure 5 Structure of the critical excitation problem 


$$
\begin{aligned}
& f_{1}(t ; \omega) C_{u v}(\omega) \\
& \quad+f_{2}(t ; \omega) Q_{u v}(\omega)
\end{aligned}
$$

Integrand in cross term

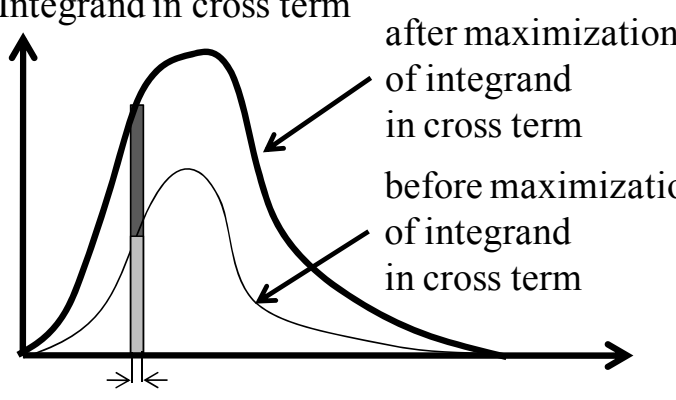

$d \omega$

Searching for co-spectrum and quad-spectrum which maximize integrand of cross term for each fixed frequency

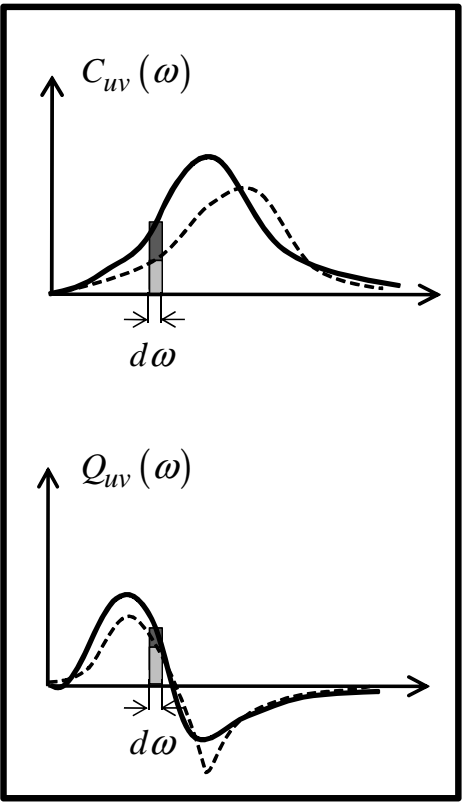

Figure 6 Solution algorithm of the critical excitation problem

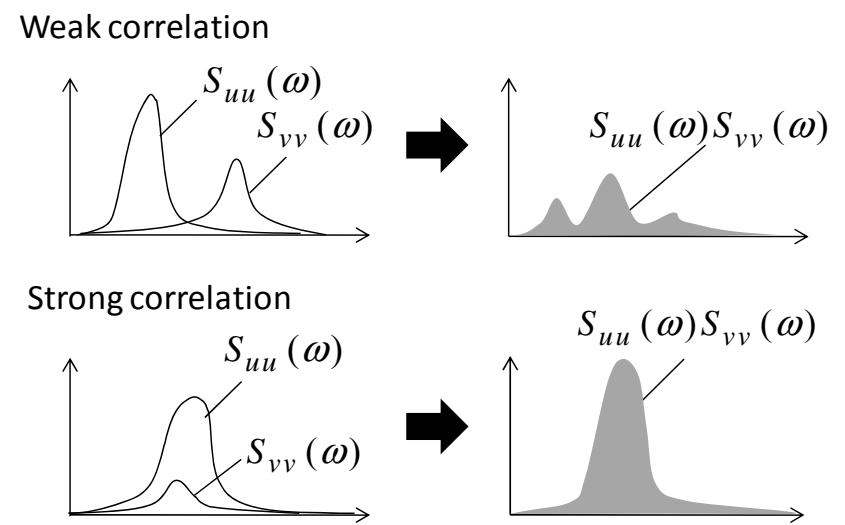

Figure 7 Relationship between horizontal and vertical PSD functions with regard to the response increase effect caused by correlation

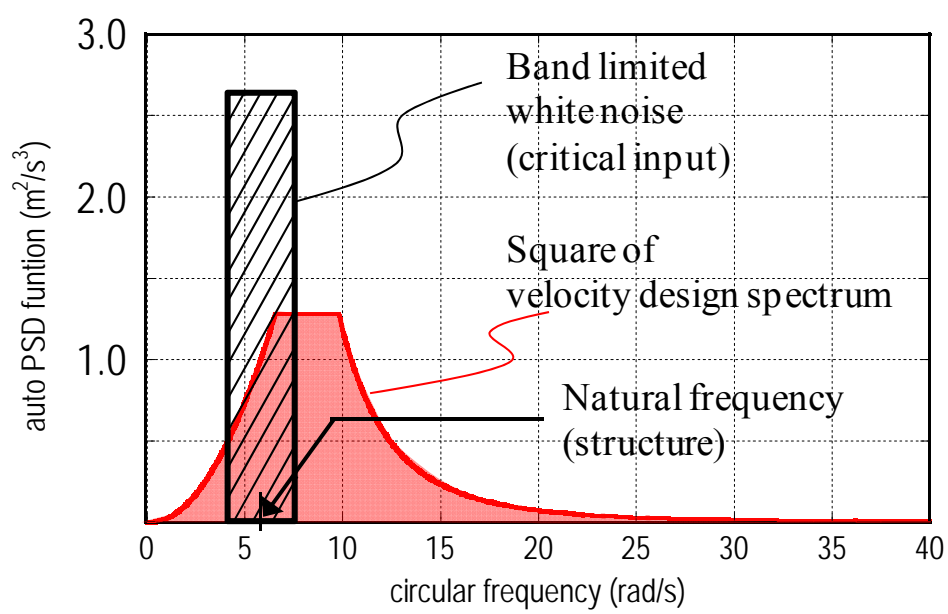

Figure 8 Relationship between auto PSD functions (band limited white noise and design spectrum) 


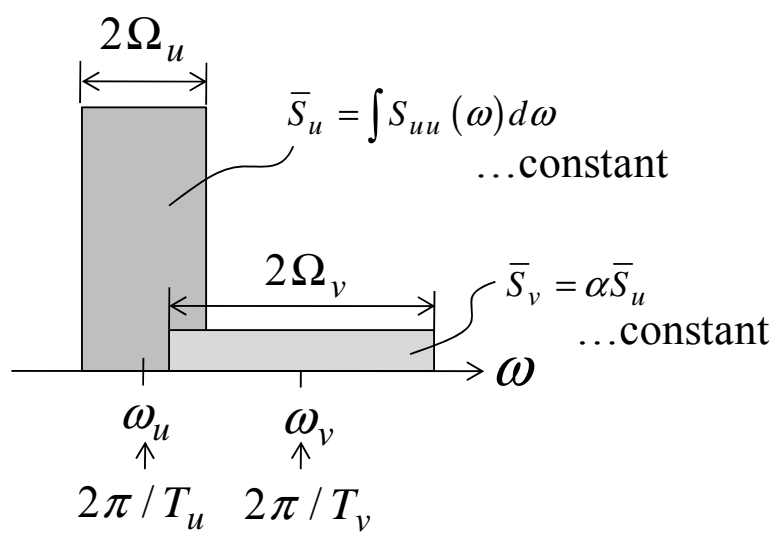

Figure 9 Variable PSD functions in respective directions

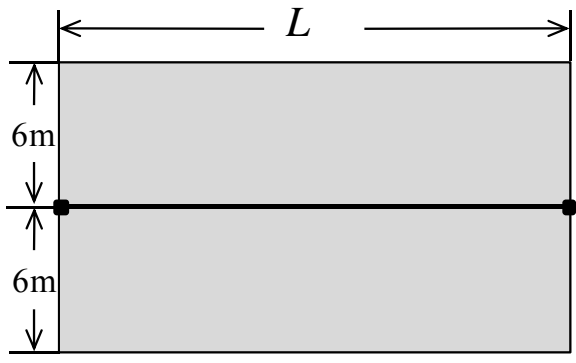

plan

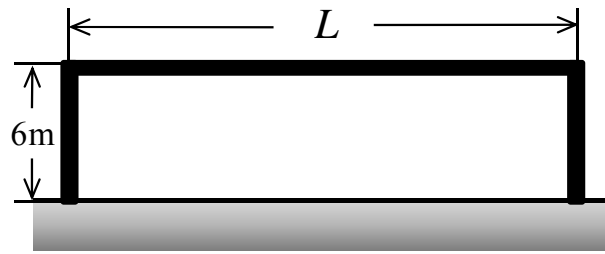

elevation

Figure 10 One-story one-span moment resisting frame

(a)

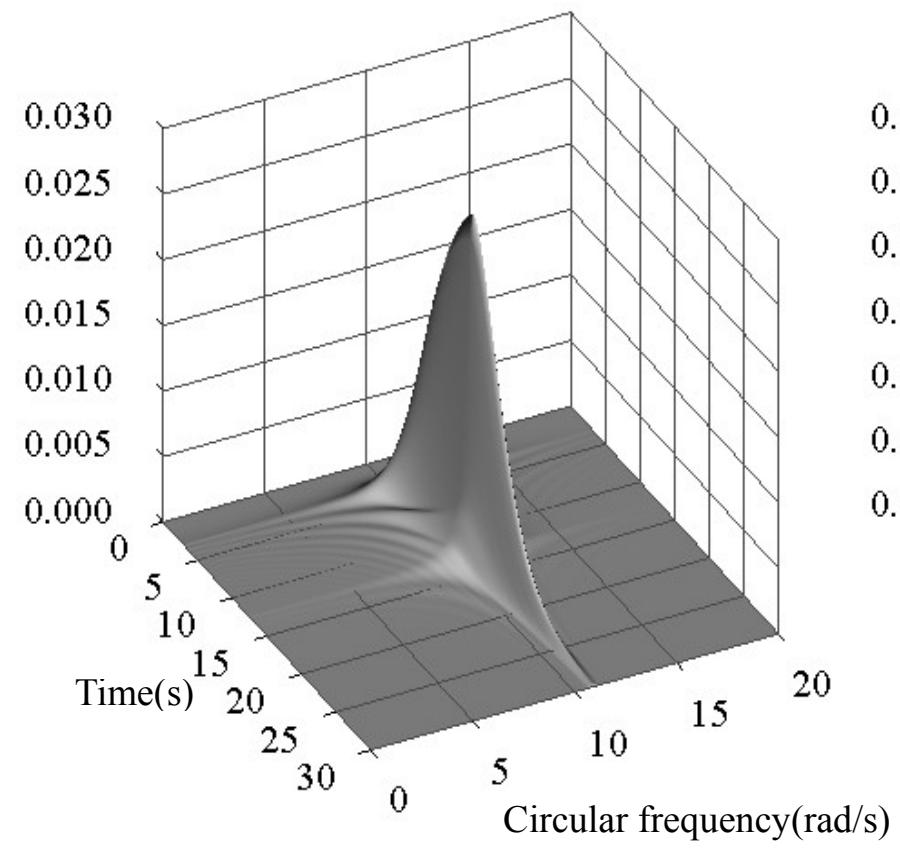

(b)

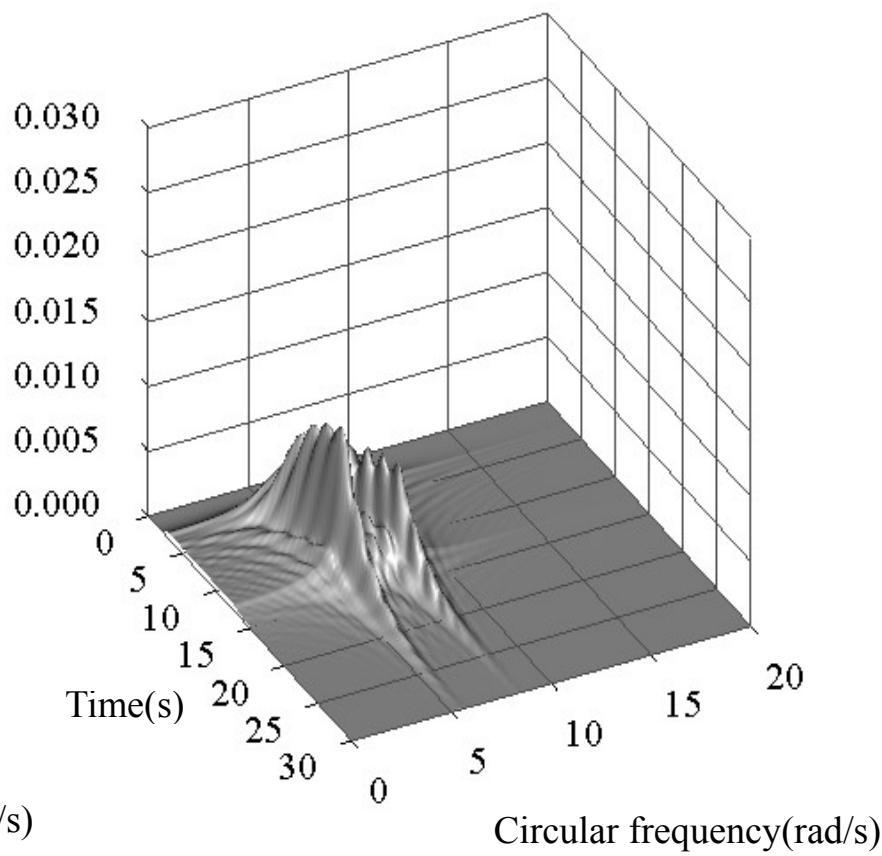

Figure 11 Transfer function $\sqrt{f_{1}(t ; \omega)^{2}+f_{2}(t ; \omega)^{2}}$, (a) $L=17 \mathrm{~m} \quad$ (b) $L=24 \mathrm{~m}$ 
(a)

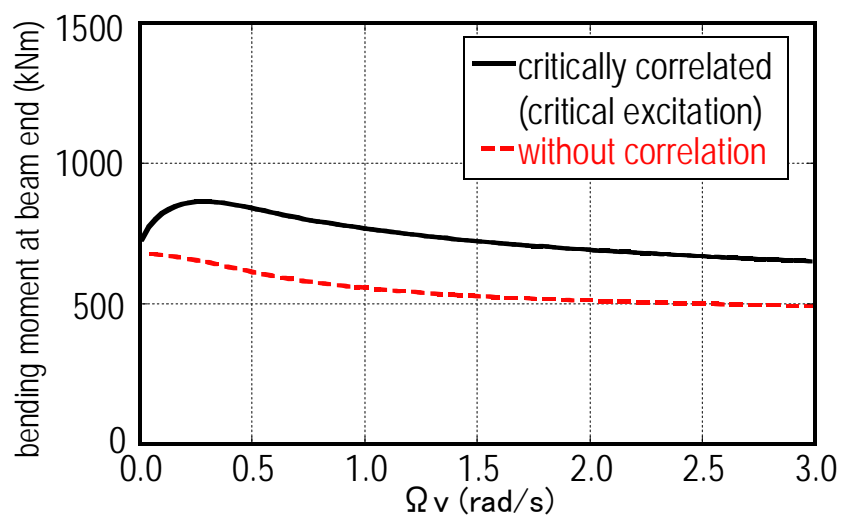

(b)

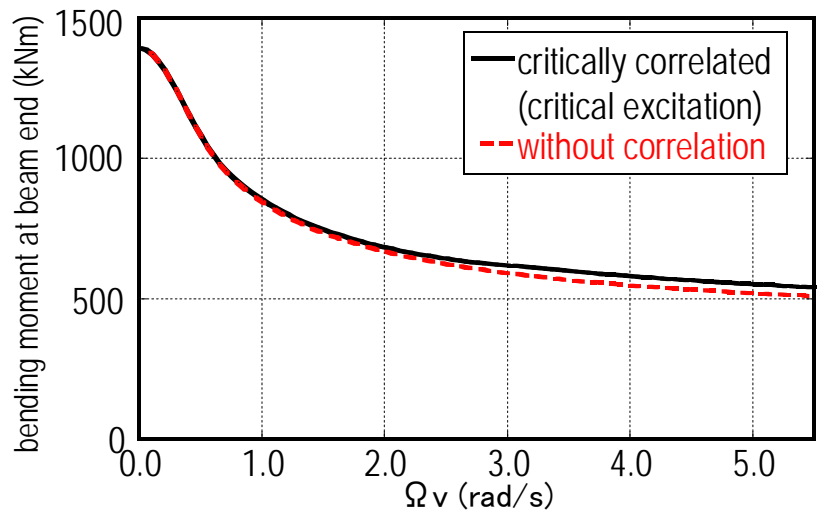

Figure 12 Comparison of the RMS bending moment to critically correlated multi-input with that to multi-input without correlation, (a) $L=17 \mathrm{~m}$, (b) $L=24 \mathrm{~m}$

(a)

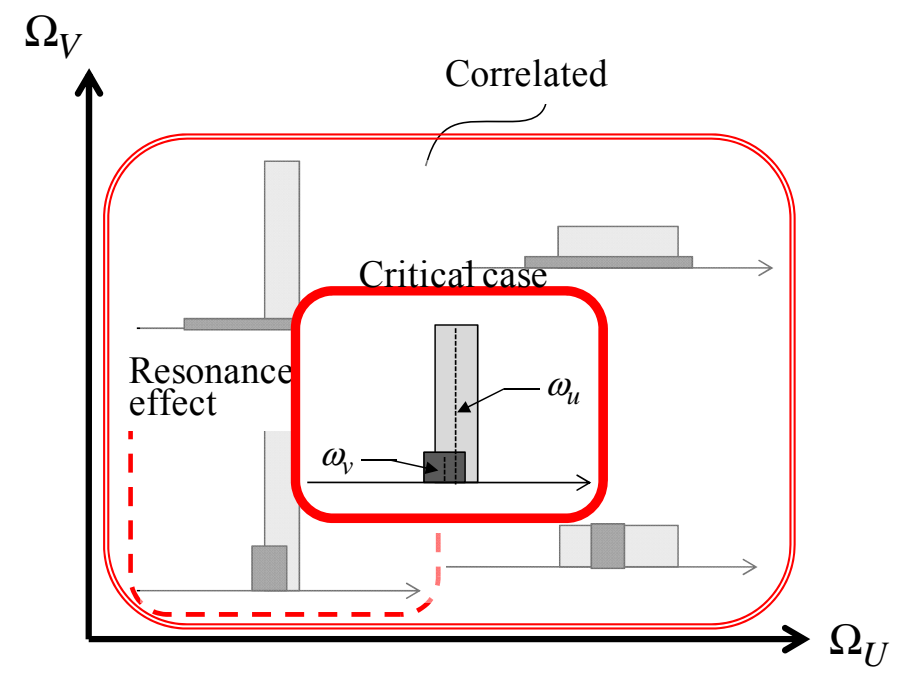

(b)

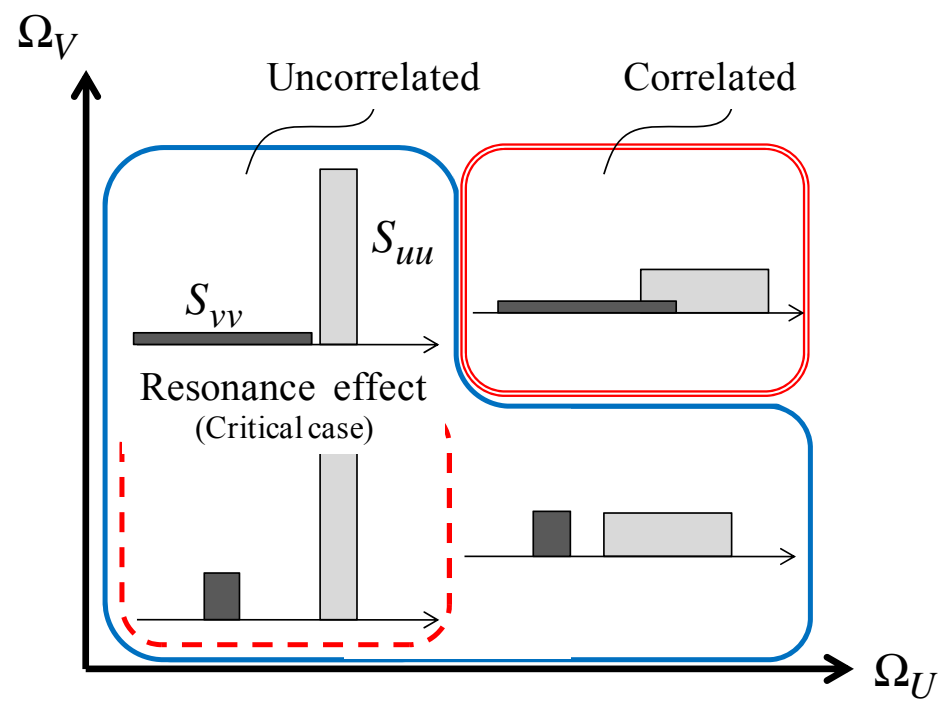

Figure 13 Critical combination of auto PSD functions of HVGM, (a) $L=17 \mathrm{~m}$, (b) $L=24 \mathrm{~m}$ 
$(\mathrm{a}-1)$

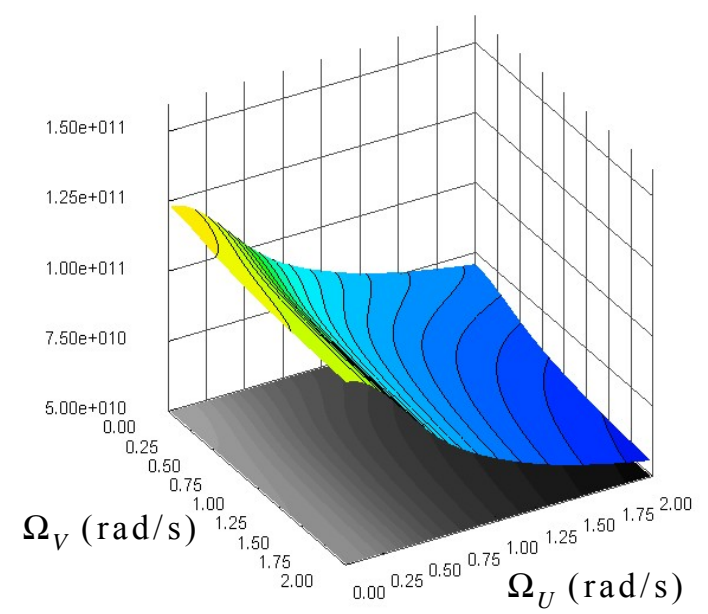

(b-1)

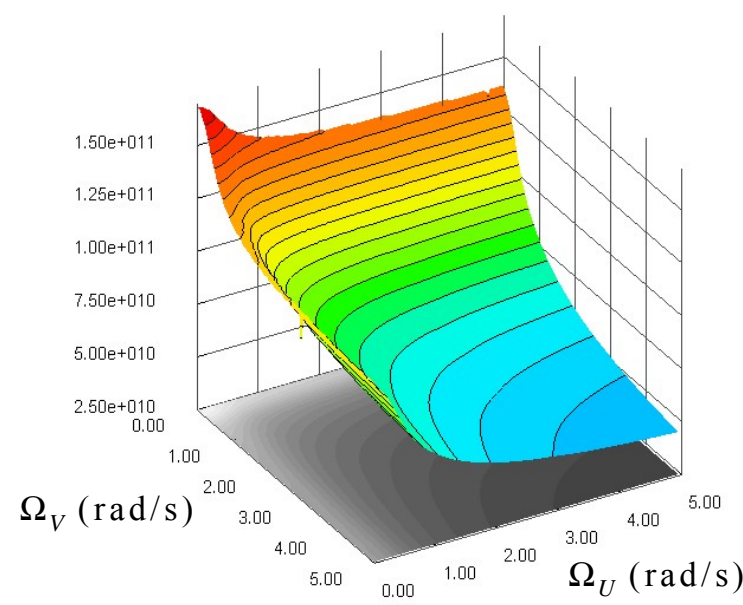

\section{$(\mathrm{a}-2)$}
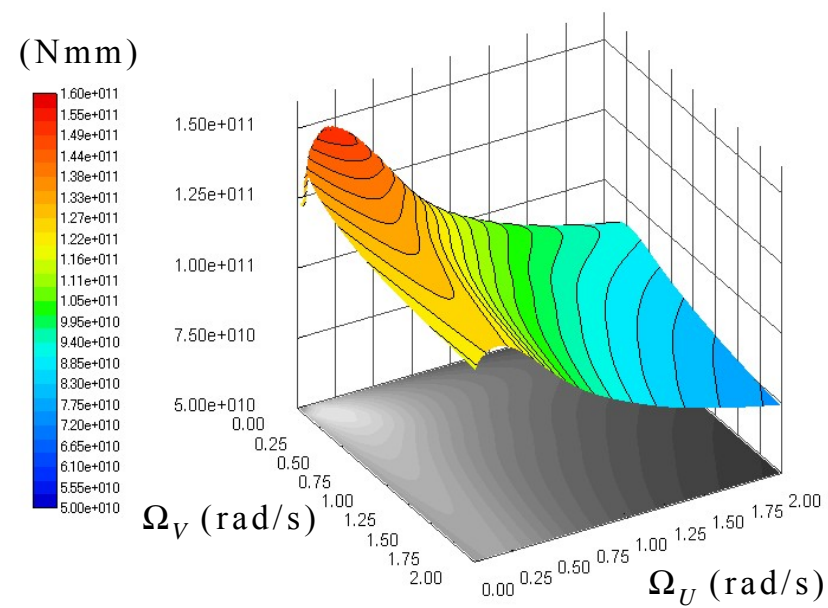

$(\mathrm{Nmm})$

(b-2)
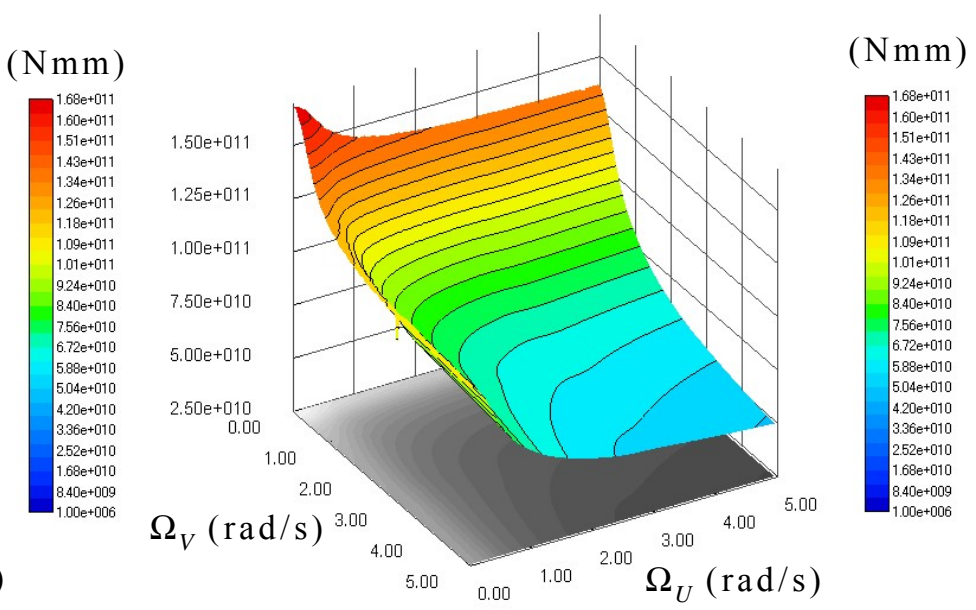

Figure 14 Three-dimentional comparison of the RMS bending moment to critically correlated multi-input with that to multi-input without correlation,

(a-1, b-1), without correlation $(L=17 \mathrm{~m}, L=24 \mathrm{~m}),(\mathrm{a}-2, \mathrm{~b}-2)$, critically correlated $(L=17 \mathrm{~m}, L=24 \mathrm{~m})$ 
(a)

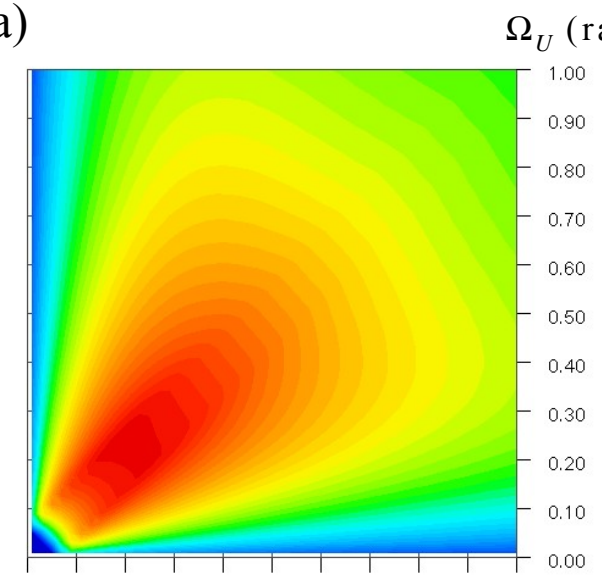

$\begin{array}{lllllllllll}0.00 & 0.10 & 0.20 & 0.30 & 0.40 & 0.50 & 0.60 & 0.70 & 0.80 & 0.90 & 1.00\end{array}$ $\Omega_{V}(\mathrm{rad} / \mathrm{s})$ (b)

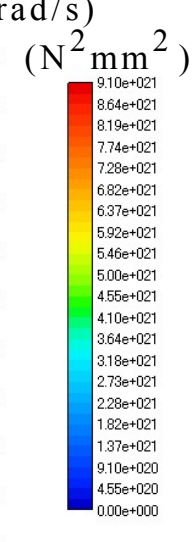

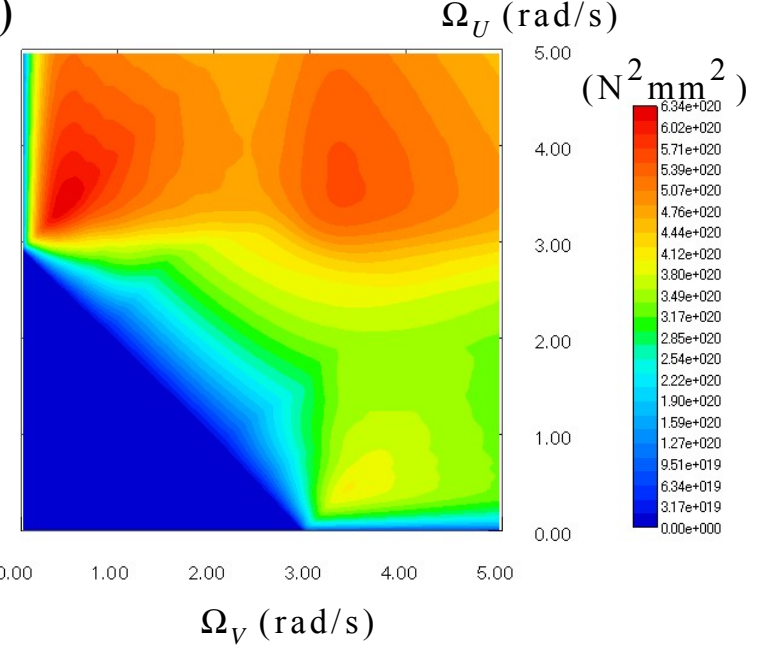

Figure 15 Quantity of Eq.(29) for critically correlated multi-input with respect to $\Omega_{U}$ and $\Omega_{V}$ (a) $L=17 \mathrm{~m}$, (b) $L=24 \mathrm{~m}$ 